Check for updates

Cite this: Chem. Sci., 2017, 8, 7174

Received 7th July 2017

Accepted 24th August 2017

DOI: $10.1039 / \mathrm{c} 7 \mathrm{sc} 02986 a$

rsc.li/chemical-science

\title{
A $\beta$-Carbon elimination strategy for convenient in situ access to cyclopentadienyl metal complexes $\uparrow$
}

\author{
G. Smits, $\dot{t}^{\mathrm{a}}$ B. Audic, (D) ${ }^{\mathrm{a}}$ M. D. Wodrich, (DD ${ }^{\mathrm{b}}$ C. Corminboeuf (D) ${ }^{* b}$ and N. Cramer (D) *a \\ The electronic and steric properties of tailored cyclopentadienyl $(\mathrm{Cp})$ ligands are powerful handles to \\ modulate the catalytic properties of their metal complexes. This requires the individual preparation, \\ purification and storage of each ligand/metal combination. Alternative, ideally in situ, complexation \\ protocols would be of high utility. We disclose a new approach to access Cp metal complexes. \\ Common metal precursors rapidly react with cyclopentadienyl carbinols via $\beta$-carbon eliminations to \\ directly give the $\mathrm{Cp}$-metal complexes. An advantage of this is the direct and flexible use of storable pre- \\ ligands. No auxiliary base is required and the $\mathrm{Cp}$ complexes can be prepared in situ in the reaction vessel \\ for subsequent catalytic transformations.
}

\section{Introduction}

Cyclopentadienyl (Cp)-coordinated transition-metal complexes are ubiquitous and many of them are efficient catalysts for a broad range of versatile, atom-economic transformations. ${ }^{1}$ Many of these reactions have highly optimized conditions, but use commercially available complexes with a conserved $\mathrm{Cp}^{*}$ or $\mathrm{Cp}$ ligand. Only recently, the modulation of the electronic and steric properties of tailored $\mathrm{Cp}$ ligands was recognized as a powerful tool to overcome sluggish reactivity, ${ }^{2}$ to address regio- and positional issues, ${ }^{3}$ and provide entry to enantioselective processes. ${ }^{4}$ In rapid reaction discovery and optimization, the ability to combine a library of ligands with a library of metal complexes, performing an in situ complexation to give the desired catalyst species is a relevant advantage. While this approach is very common for reactions involving, for instance, phosphine ligands, it is still elusive for Cp ligands. In this case, each ligand/metal combination has to be synthesized individually, purified and stocked prior to any use in catalysis. The typical complexation of common $\mathrm{Cp}^{*}$ and $\mathrm{Cp}$ complexes involves the metal as a limiting reagent. ${ }^{5}$ However, highly elaborate $\mathrm{Cp}$ or chiral $\mathrm{Cp}^{\mathrm{x}}$ ligands require the use of the $\mathrm{CpH}$ derivative as the limiting reactant. In particular for chiral $\mathrm{Cp}^{\mathrm{x}}$ ligands, one has to rely on undesirable reaction conditions, for example involving thallium alkoxide in benzene. ${ }^{\mathbf{4}, \mathbf{6}}$ These shortcomings make the development of complementary

\footnotetext{
${ }^{a}$ Laboratory of Asymmetric Catalysis and Synthesis, EPFL SB ISIC LCSA, BCH 4305, CH-1015 Lausanne, Switzerland. E-mail: nicolai.cramer@epfl.ch

${ }^{b}$ Laboratory for Computational Molecular Design, EPFL SB ISIC LCMD, BCH 5312, CH-1015 Lausanne, Switzerland. E-mail: clemence.corminboeuf@epfl.ch

$\dagger$ Electronic supplementary information (ESI) available: Experimental procedures and characterisation of all new compounds. See DOI: 10.1039/c7sc02986a

\$ Present address: Laboratory of CNS Active Compounds, Latvian Institute of Organic Synthesis, Aizkraukles 21, LV-1006, Riga, Latvia.
}

complexation strategies a priority. Ideally, such technology proceeds rapidly and in a quantitative manner, without the generation of inhibiting reaction byproducts. It should also be useable with a range of different transition-metals.

$\beta$-Carbon elimination has been reported as a complementary method to access organometallic species in catalysis. ${ }^{7}$ Normally the forward reaction - the addition across a carbonyl group - is favored and reversing this pathway requires some additional driving force. This could be a combination of using the right transition-metal and the use of substrates leading to the formation of stronger $\mathrm{C}_{\mathrm{sp}}-[\mathrm{M}]^{8}$ or $\mathrm{C}_{\mathrm{sp}^{2}}-[\mathrm{M}]$ bonds. ${ }^{9}$ The gener-

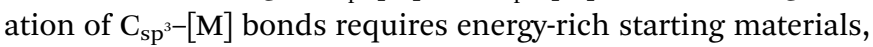
such as tert-cyclobutanols ${ }^{\mathbf{1 0}}$, releasing strain upon $\beta-\mathrm{C}$ elimination. ${ }^{11}$ A particular class of substrate is that of homoallylic alcohols that can give $\pi$-bound allyl-metal species by retroallylation. ${ }^{12}$ Along the same lines, a cyclopentadienyl carbinol would give a $\mathrm{Cp}-[\mathrm{M}]$ species upon $\mathrm{C}-\mathrm{C}$ bond cleavage. The very strong bond of the cyclopentadienyl anion to the transitionmetal would be a very strong driving force. So far, the $\beta-\mathrm{C}$ elimination methodology has been used exclusively as an elementary step in catalytic transformations. Herein we exploit its potential for the preparation of $\mathrm{Cp}$-metal complexes (Scheme 1).

\section{Results and discussion}

The required cyclopentadienyl carbinol substrates for the preligands are accessed in a straight forward manner by deprotonation and addition across the desired aldehyde or ketone (Scheme 2, see ESI $\dagger$ for details). ${ }^{13}$ In contrast to many lightly substituted cyclopentadienes which frequently undergo DielsAlder dimerization, all prepared $\mathrm{Cp}$-carbinols are stable and do not dimerize upon storage. Exemplarily for $[\mathrm{Rh}(\operatorname{cod}) \mathrm{OH}]_{2}$, ligand exchange of the hydroxy ligand by 2 would break up the 


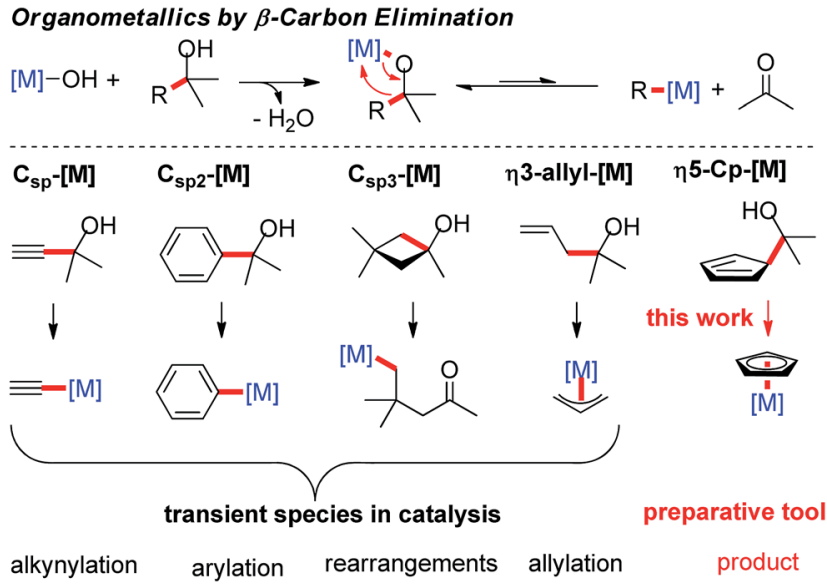

Scheme 1 Generation of organometallics using the $\beta$-carbon elimination strategy.

a)

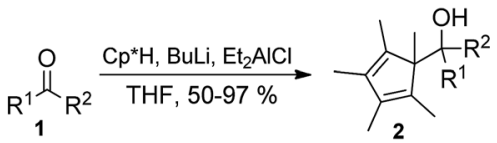

b)

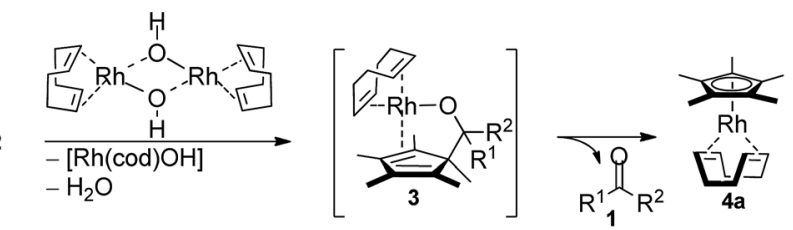

Scheme 2 (a) Synthesis of Cp pre-ligand carbinols 2. (b) Envisioned $\beta$ $\mathrm{C}$ elimination to access $\mathrm{Cp}$ *Rh(I) complexes.

dimer and release a molecule of water to give intermediate $\mathbf{3}$. In turn, 3 is predisposed for the final $\beta$-C elimination step to yield the Cp metal complex $\mathbf{4 a}$ and ketone $\mathbf{1}$.

A selection of carbinols with sterically and electronically different substituents, $\mathrm{R}^{1}$ and $\mathrm{R}^{2}$, were initially evaluated (Table 1). A variety of factors influenced the reaction performance. An aromatic substituent $\mathrm{R}^{1}$ or $\mathrm{R}^{2}$ was found to be beneficial for yield and reactivity. A tertiary hydroxyl group is better than a secondary one. Strained ketone derived $\mathbf{2 f}$ and $\mathbf{2 g}$ (entries 6-7) partially underwent the alternative strain-release pathway, ${ }^{\mathbf{1 0}}$ opening the four-membered ring instead of leading to the $\mathrm{Cp}$ metal species. Most substrates required the addition of cesium carbonate for shorter reaction times. Without the rhodium complex, carbinols 2 are stable and no conversion to free $\mathrm{Cp}^{*} \mathrm{H}$ was observed. Notably, some substrates displayed significantly increased reactivity and did not require the addition of any base (entries 8, 10, 13, and 15). The two fastest reactions were $2 \mathbf{h}\left(\mathrm{Ph} / \mathrm{CO}_{2} \mathrm{Me}\right)$ and $2 \mathbf{m}(\mathrm{Ph} / \mathrm{Me})$.

Among the tested substrates, the dimethyl-type carbinol moiety was further investigated, despite its lower reactivity, as it releases only volatile acetone as a byproduct (Table 2). It provides a clean complexation giving a range of complexes 4 with different bulks, ranging from $\mathrm{Me}_{3} \mathrm{Cp}$ (entry 1) to $t \mathrm{BuMe}_{4} \mathrm{Cp}$ (entry 5). While substrates with bulky groups react very
Table 1 Evaluation of the influence of the carbinol substituents on $\beta$ C elimination ${ }^{a}$

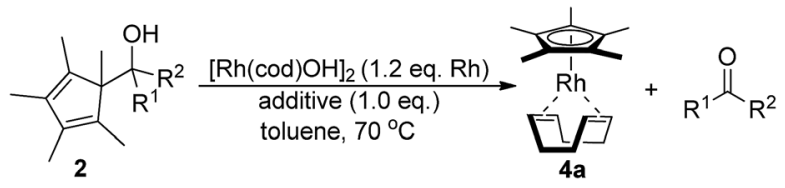

\begin{tabular}{|c|c|c|c|c|c|c|}
\hline Entry & 2 & $\mathrm{R}^{1}$ & $\mathrm{R}^{2}$ & Additive & Time & $\%$ yield $^{b}$ \\
\hline 1 & $2 a$ & $\mathrm{H}$ & $n$ Pentyl & $\mathrm{Cs}_{2} \mathrm{CO}_{3}$ & $3 \mathrm{~h}$ & 39 \\
\hline 2 & $2 b$ & $\mathrm{H}$ & $\mathrm{Ph}$ & $\mathrm{Cs}_{2} \mathrm{CO}_{3}$ & $1 \mathrm{~h}$ & 95 \\
\hline 3 & $2 c$ & $\mathrm{H}$ & $\mathrm{CO}_{2} \mathrm{Et}$ & $\mathrm{Cs}_{2} \mathrm{CO}_{3}$ & $3 \mathrm{~h}$ & 10 \\
\hline 4 & $2 d$ & Me & Me & $\mathrm{Cs}_{2} \mathrm{CO}_{3}$ & $3 \mathrm{~h}$ & 99 \\
\hline 5 & $2 e$ & $\mathrm{CH}_{2}(\mathrm{CH}$ & $\mathrm{CH}_{2}$ & $\mathrm{Cs}_{2} \mathrm{CO}_{3}$ & $3 \mathrm{~h}$ & 93 \\
\hline 6 & $2 f$ & $\mathrm{CH}_{2} \mathrm{CH}$ & & $\mathrm{Cs}_{2} \mathrm{CO}_{3}$ & $1 \mathrm{~h}$ & 30 \\
\hline 7 & $2 g$ & $\mathrm{CH}_{2} \mathrm{OC}$ & & $\mathrm{Cs}_{2} \mathrm{CO}_{3}$ & $3 \mathrm{~h}$ & 20 \\
\hline 8 & $2 h$ & $\mathrm{CO}_{2} \mathrm{Me}$ & Ph & - & $15 \mathrm{~min}$ & 75 \\
\hline 9 & $2 \mathbf{i}$ & $\mathrm{CO}_{2} \mathrm{Me}$ & $\mathrm{Me}$ & $\mathrm{Cs}_{2} \mathrm{CO}_{3}$ & $3 \mathrm{~h}$ & 75 \\
\hline 10 & $2 j$ & $\mathrm{CO}_{2} \mathrm{Me}$ & $t \mathrm{Bu}$ & - & $1 \mathrm{~h}$ & 45 \\
\hline 11 & $2 \mathbf{k}$ & $\mathrm{CO}_{2} \mathrm{Me}$ & $\mathrm{CF}_{3}$ & $\mathrm{Cs}_{2} \mathrm{CO}_{3}$ & $1 \mathrm{~h}$ & $<5$ \\
\hline 12 & 21 & $\mathrm{CO}_{2} \mathrm{Et}$ & $\mathrm{CO}_{2} \mathrm{Et}$ & $\mathrm{Cs}_{2} \mathrm{CO}_{3}$ & $3 \mathrm{~h}$ & $<5$ \\
\hline 13 & $2 \mathrm{~m}$ & Me & Ph & - & $15 \mathrm{~min}$ & 89 \\
\hline 14 & $2 n$ & $\mathrm{Me}$ & Cy & $\mathrm{Cs}_{2} \mathrm{CO}_{3}$ & $3 \mathrm{~h}$ & 80 \\
\hline 15 & 20 & $\mathrm{CF}_{3}$ & $\mathrm{Ph}$ & - & $1 \mathrm{~h}$ & 95 \\
\hline
\end{tabular}

${ }^{a}$ Conditions: $\mathrm{N}_{2}$ atmosphere, $0.040 \mathrm{mmol} 2,0.024 \mathrm{mmol}[\mathrm{Rh}(\operatorname{cod}) \mathrm{OH}]_{2}$, $0.040 \mathrm{mmol}$ additive, $0.2 \mathrm{M}$ in toluene at $70{ }^{\circ} \mathrm{C}$ for the indicated time.

${ }^{b}$ Yield determined by NMR with an internal standard.

smoothly, less substituted ones like the trimethyl Cp precursor 5b react less efficiently due to some fulvene byproduct formation. Indenyl complexes can be prepared with similar efficiency (entries 6-7). Methyl phenylglyoxylate and acetophenone derived pre-ligands $\mathbf{5 i}$ and $\mathbf{5 j}$ are easier to access and better suited in the complexation giving, as before, fast and clean transformations without the requirement of a basic additive (entries 8-9). Importantly, this complexation strategy is equally successful for chiral $\mathrm{Cp}^{*}$ ligands equipped with our atropchiral backbone. ${ }^{4 f-i}$ Importantly, the $\beta$-C eliminative complexation is not limited to rhodium. For instance, using $[\operatorname{Ir}(\operatorname{cod}) \mathrm{OH}]_{2}$ as the metal salt provided access to indenyl $\operatorname{Ir}(\operatorname{cod})$ and cyclopentadienyl complexes 69-6j in comparable yields (entries 6-9). Exposure of the chiral $\mathrm{Cp}^{\mathrm{x} *}$ pre-ligand $5 \mathbf{k}$ to the reaction conditions induced a smooth complexation, providing rhodium complex $\mathbf{4 k}$ in $93 \%$ yield (entry 10 ). This is particularly noteworthy as classical complexation methods ${ }^{4 d_{\boldsymbol{I}} \boldsymbol{f}}$ for a di-substituted chiral $\mathrm{Cp}^{\mathrm{x}}$ ligand failed completely for this chiral pentasubstituted analog. Analogously, the chiral iridium complex 6k could be obtained in $87 \%$ yield. Moreover, we could extend the method for the preparation of a chiral $\mathrm{Cp}^{\mathrm{x} *} \mathrm{Co}^{\mathrm{III}}$ complex $7 \mathbf{k}$ (entry 11). For the first time, chiral fully penta-substituted cyclopentadienyl rhodium, iridium and cobalt complexes are now accessible. This sets the stage for future applications in asymmetric catalysis, especially for transformations where previously reported complexes with the disubstituted chiral variants $^{4 a, b}$ failed to provide adequate reactivity.

Besides the hydroxyl bridged dimer, other $[\mathrm{Rh}(\operatorname{cod}) \mathrm{X}]_{2}$ complexes ( $\mathrm{X}=\mathrm{OMe}$, OAc, and $\mathrm{Cl}$ ) can be used (Table 3, entries 
Table 2 Scope for Cp complexation by $\beta$-C elimination ${ }^{a}$

$\mathrm{Cs}_{2} \mathrm{CO}_{3}(1.0 \mathrm{eq}$.
toluene, $70^{\circ} \mathrm{C}$

\begin{tabular}{llllll}
\hline Entry & $\mathbf{5}$ & $\mathrm{R}^{1}$ & $\mathrm{R}^{2}$ & $\mathbf{4}$ & \% yield \\
\hline
\end{tabular}

$1 \quad 5 b \quad$ Me $\quad$ Me

$\begin{array}{llll}2 & \mathbf{5 c} & \mathrm{Me} & \mathrm{Me} \\ 3 & \mathbf{5 d} & \mathrm{Me} & \mathrm{Me} \\ 4 & \mathbf{5 e} & \mathrm{Me} & \mathrm{Me} \\ 5 & \mathbf{5 f} & \mathrm{Me} & \mathrm{Me}\end{array}$

$6^{d} \quad \mathbf{5 g} \quad \mathrm{Me} \quad \mathrm{Me}$

5h $\quad \mathrm{Me} \quad \mathrm{Me}$

$8^{c, d} \quad 5 \mathbf{i} \quad \mathrm{Ph} \quad \mathrm{CO}_{2} \mathrm{Me}$

$9^{c, d} \quad 5 \mathbf{j} \quad \mathrm{Ph} \quad \mathrm{Me}$

$10^{d} \quad 5 \mathbf{k} \quad \mathrm{Ph} \quad \mathrm{CO}_{2} \mathrm{Me}$

$11^{f} \quad 5 k \quad \mathrm{Ph} \quad \mathrm{CO}_{2} \mathrm{Me}$

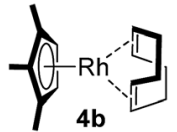

42

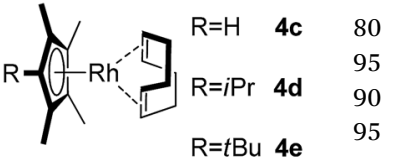

$\mathrm{R}=\mathrm{Ph} \quad \mathbf{4 f}$

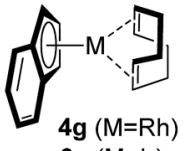

$6 \mathrm{~g}(\mathrm{M}=\mid \mathrm{r})$
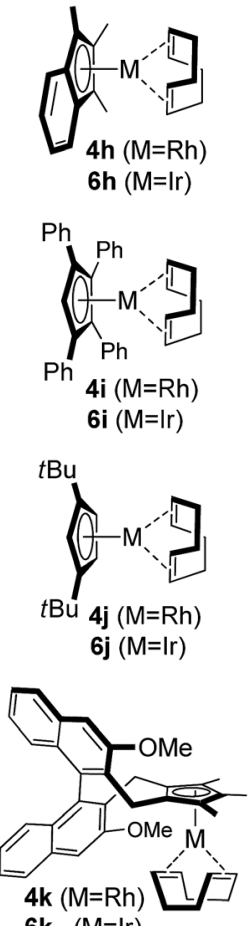

6k $(\mathrm{M}=\mathrm{Ir})$

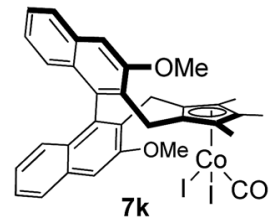

$32^{e}$ $90(\mathbf{4 g})$

$88(6 \mathrm{~g})$

$95(\mathbf{4 h})$

$86(6 \mathbf{h})$

$60(4 \mathbf{i})$

$44(6 j)$

$95(4 \mathbf{j})$

$63(6 \mathbf{j})$

$93(\mathbf{4 k})^{e}$

$87(6 \mathbf{k})^{e}$

${ }^{a}$ Conditions: $0.04 \mathrm{mmol} \mathrm{5}, 0.024 \mathrm{mmol}$ of $[\mathrm{Rh}(\operatorname{cod}) \mathrm{OH}]_{2}, 0.040 \mathrm{mmol}$ $\mathrm{Cs}_{2} \mathrm{CO}_{3}, 0.2 \mathrm{~mL}$ toluene at $70{ }^{\circ} \mathrm{C}, 15 \mathrm{~min}-10 \mathrm{~h} .{ }^{b}$ Determined by NMR with an internal standard. ${ }^{c} 4 \AA$ molecular sieves instead of $\mathrm{Cs}_{2} \mathrm{CO}_{3}$ at $23{ }^{\circ} \mathrm{C}$. ${ }^{d}$ With $[\mathrm{Ir}(\operatorname{cod}) \mathrm{OH}]_{2}$ for $6 .{ }^{e}$ Isolated yield. ${ }^{f}$ Conditions: $0.06 \mathrm{mmol}$ 5k and $36 \mu \mathrm{mol} \mathrm{Co} 2(\mathrm{CO})_{8}, 0.4 \mathrm{~mL} \mathrm{CH}_{2} \mathrm{Cl}_{2}$ at $40{ }^{\circ} \mathrm{C}$, then $\mathrm{I}_{2}(0.06 \mathrm{mmol})$.
Table 3 Scope with different transition-metal precursors ${ }^{a}$

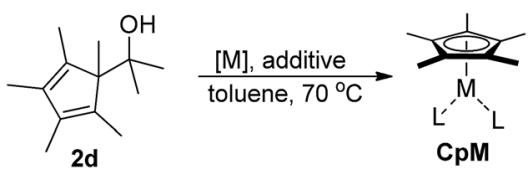

\begin{tabular}{llllll}
\hline Entry & $\mathrm{CpM}$ & {$[\mathrm{M}]$} & Additive & Time & \% yield \\
\hline 1 & $\mathbf{4 a}$ & {$[\mathrm{Rh}(\mathrm{cod}) \mathrm{OMe}]_{2}$} & $\mathrm{Cs}_{2} \mathrm{CO}_{3}$ & $3 \mathrm{~h}$ & 70 \\
2 & $\mathbf{4 a}$ & {$[\mathrm{Rh}(\mathrm{cod}) \mathrm{OAc}]_{2}$} & $\mathrm{Cs}_{2} \mathrm{CO}_{3}$ & $3 \mathrm{~h}$ & 70 \\
3 & $\mathbf{4 a}$ & {$[\mathrm{Rh}(\mathrm{cod}) \mathrm{Cl}]_{2}$} & $\mathrm{KOH}$ & $3 \mathrm{~h}$ & 90 \\
4 & $\mathbf{4 l}$ & {$[\mathrm{Rh}(\mathrm{nbd}) \mathrm{Cl}]_{2}$} & $\mathrm{KOH}$ & $2 \mathrm{~h}$ & 80 \\
5 & $\mathbf{4 l}$ & {$[\mathrm{Rh}(\mathrm{nbd}) \mathrm{OH}]_{2}$} & $\mathrm{Cs}_{2} \mathrm{CO}_{3}$ & $3 \mathrm{~h}$ & 99 \\
6 & $\mathbf{4 m}$ & {$\left[\mathrm{Rh}(\mathrm{CO})_{2} \mathrm{Cl}\right]_{2}$} & $\mathrm{KOH}_{2}$ & $15 \mathrm{~min}$ & 49 \\
7 & $\mathbf{6 a}$ & {$[\mathrm{Ir}(\mathrm{cod}) \mathrm{OH}]_{2}$} & $\mathrm{Cs}_{2} \mathrm{CO}_{3}$ & $5 \mathrm{~h}$ & 92 \\
$8^{c}$ & $\mathbf{8}$ & {$\left[\mathrm{Co}(\mathrm{CO})_{8}\right]$} & - & $6 \mathrm{~h}$ & 60 \\
9 & $\mathbf{4 n}$ & {$\left[\mathrm{Rh}\left(\mathrm{C}_{2} \mathrm{H}_{4}\right)_{2} \mathrm{OAc}\right]_{2}$} & $\mathrm{Cs}_{2} \mathrm{CO}_{3}$ & $1 \mathrm{~h}$ & 10 \\
$10^{d}$ & $\mathbf{4 n}$ & {$\left[\mathrm{Rh}\left(\mathrm{C}_{2} \mathrm{H}_{4}\right)_{2} \mathrm{Cl}\right]_{2}$} & $\mathrm{KOH}_{4} \AA \mathrm{MS}$ & $5 \mathrm{~h}$ & 70 \\
$11^{e}$ & $\mathbf{4 o}$ & {$\left[\mathrm{Rh}\left(\mathrm{C}_{2} \mathrm{H}_{3} \mathrm{TMS}\right) \mathrm{Cl}\right]_{2}$} & $\mathrm{KOH}, 4 \AA \mathrm{MS}$ & $1 \mathrm{~h}$ & $66^{f}$
\end{tabular}

${ }^{a}$ Conditions: $0.04 \mathrm{mmol} 2 \mathrm{~d}, 24 \mu \mathrm{mol}[\mathrm{M}], 0.04 \mathrm{mmol} \mathrm{Cs}_{2} \mathrm{CO}_{3}$ or $0.12 \mathrm{mmol} \mathrm{KOH}, 0.2 \mathrm{~mL}$ toluene. ${ }^{b}$ Determined by NMR with an internal standard. ${ }^{c}$ Conditions: $0.06 \mathrm{mmol} 2 \mathrm{~d}$ and $36 \mu \mathrm{mol} \mathrm{Co}_{2}(\mathrm{CO})_{8}$, $0.4 \mathrm{~mL} \mathrm{CH} \mathrm{Cl}_{2}$ at $40{ }^{\circ} \mathrm{C}$. ${ }^{d}$ With $2 \mathrm{~m}$ instead of $2 \mathrm{~d}$ at $23{ }^{\circ} \mathrm{C}$. ${ }^{e}$ With $2 \mathrm{~m}$ instead of $2 \mathbf{d} .{ }^{f}$ Isolated yield.

1-3). The chloride containing complexes require the addition of $\mathrm{KOH}$ for an in situ exchange. Moreover, $[\mathrm{Rh}(\mathrm{nbd}) \mathrm{X}]_{2}$ (nbd $=$ norbornadiene) and $\left[\mathrm{Rh}(\mathrm{CO})_{2} \mathrm{Cl}\right]_{2}$ work similarly (entries 4-6). Without a change in protocol, the corresponding iridium(I) complex 6a and cobalt $(0)$ complex 8 were prepared (entries 7-8). Solely the rhodium ethylene congener is not well suited for these conditions (entry 9). However, an improved protocol (vide infra) solved this issue and provided $4 \mathbf{n}$ and 40 (entries 10 and 11).

For the $\mathrm{Ph} / \mathrm{Me}$ substrate $2 \mathrm{~m}$, DFT computations (at the $\mathrm{PBE}^{14}$-dDsC ${ }^{15} / \mathrm{TZ} 2 \mathrm{P} / / \mathrm{M} 06^{16} / \mathrm{def} 2-\mathrm{SVP}$ level in implicit toluene solvent using COSMO-RS, ${ }^{17}$ see ESI $\dagger$ for additional details) provided some more details on the reaction profile of the

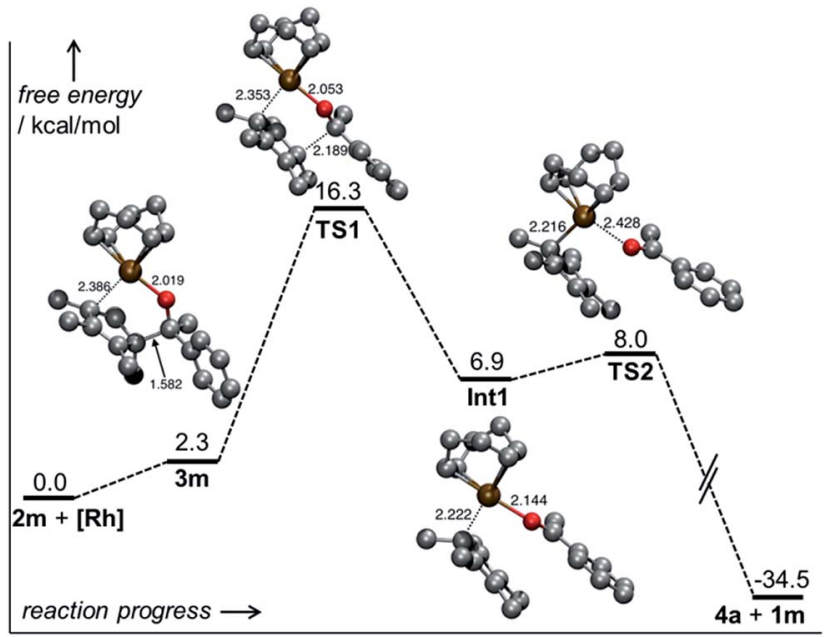

Fig. 1 Reaction profile of the $\beta$-C elimination of carbinol $2 \mathrm{~m}$. 
complexation reaction (Fig. 1). First, the $[\mathrm{Rh}(\mathrm{cod}) \mathrm{OH}]$ fragment forms complex $\mathbf{3 m}$ with the substrate carbinol. Cleavage of the C-C bond proceeds via TS1 with a barrier of only $16.3 \mathrm{kcal} \mathrm{mol}^{-1}$, which aligns well with the experimentally observed fast reaction. After $\mathrm{C}-\mathrm{C}$ cleavage, a metastable species (Int 1) is formed which quickly dissociates to the products $4 \mathbf{a}$ and $\mathbf{1 m}$ after dissociation of the ketone (TS2). The overall process is thermodynamically favourable, being exergonic by $34.5 \mathrm{kcal} \mathrm{mol}^{-1}$.

While the outlined protocol works very well for robust diene containing metal precursors, some more sensitive ones, e.g. $\left[\mathrm{Rh}\left(\mathrm{C}_{2} \mathrm{H}_{4}\right)_{2} \mathrm{OAc}\right]_{2}$ resulted in unsatisfactory yields despite full conversion. DFT computations indicated that the height of the $\beta$-C elimination barrier was not the issue. We hypothesized that the reaction rate could be negatively impacted by the increasing amount of formed water. This could compete with the sterically hindered cyclopentadienyl carbinol and be the limiting factor in
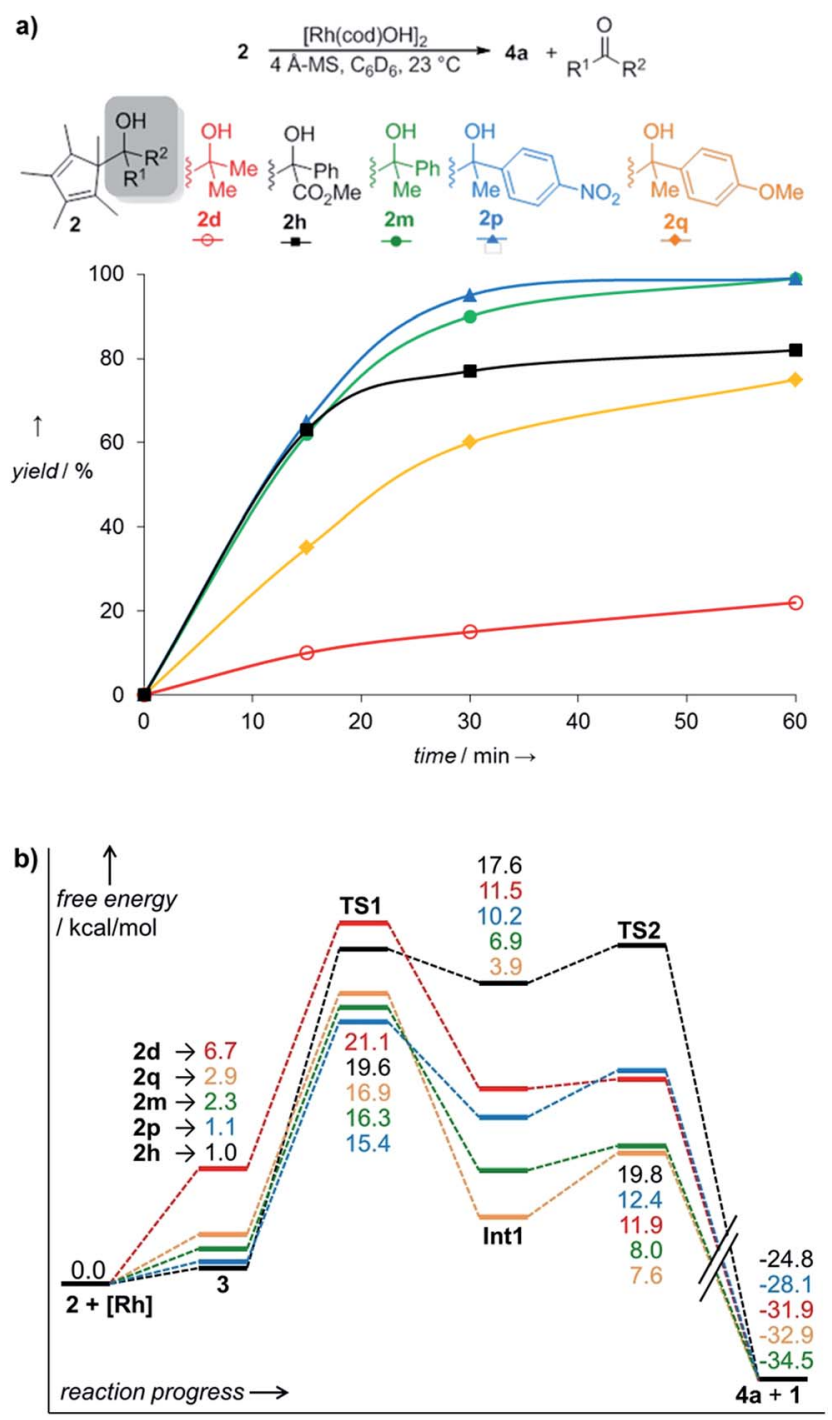

Fig. 2 (a) Complexation rates of different carbinols 2; yields of 4 a after 60 min: 2d: 22\%; 2h: $82 \%$; 2m: 99\%; 2p: 99\%; 2q: 75\%. (b) Reaction profiles of carbinols 2 during complexation. the ligand exchange of the metal hydroxy complex. Indeed, the addition of $4 \AA$ molecular sieves as traps for the generated water byproduct accelerates the reaction significantly (Table 3, entry 10). Instead of $70^{\circ} \mathrm{C}$, fast and complete complexation occurs at ambient temperature. Under these conditions, the $\beta$-carbon elimination was monitored by ${ }^{1} \mathrm{H}-\mathrm{NMR}$ spectroscopy (Fig. 2). From all of the tested substrates, the initially selected $\mathrm{Cp}^{*}$ dimethyl carbinol 2d was the slowest one. Methyl phenylglyoxylate derived substrate $\mathbf{2 h}$ initially reacts very fast, but stalls at around $80 \%$ yield. Acetophenone derived substrate $\mathbf{2 m}$ reacts smoothly and cleanly, producing the desired complex in $90 \%$ yield after 30 minutes and quantitatively after 1 hour at ambient temperature. Moreover, some dependence on the substitution pattern of the aryl group was found. For instance, the $p$-nitro derivative $2 p$ reacts fastest and the $p$-methoxy congener $\mathbf{2 q}$ is slower than the parent substrate $\mathbf{2 m}$. DFT results of this substrate set confirmed the observed reactivity trends.

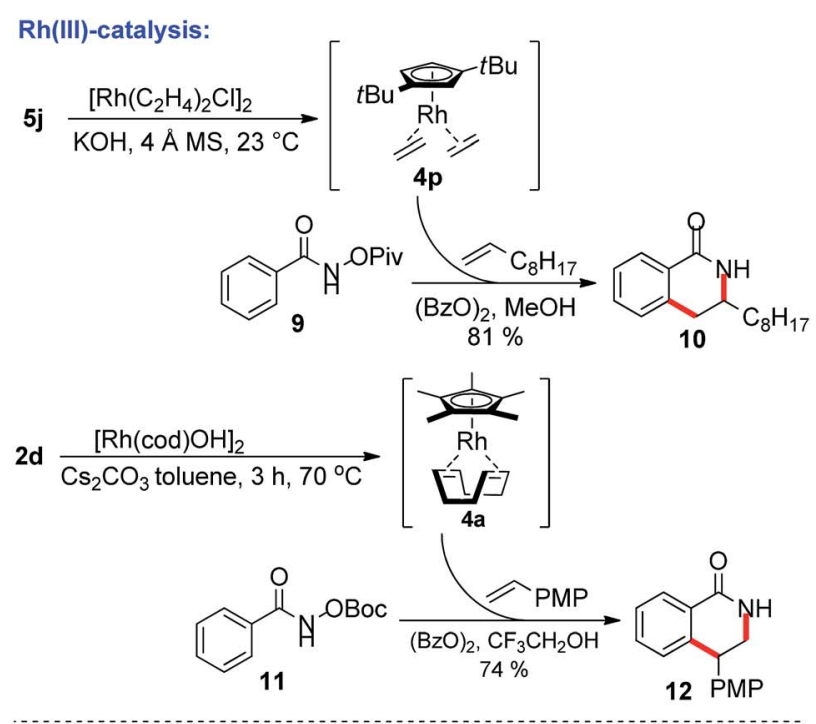

$\mathrm{Rh}(\mathrm{I})$-catalysis:
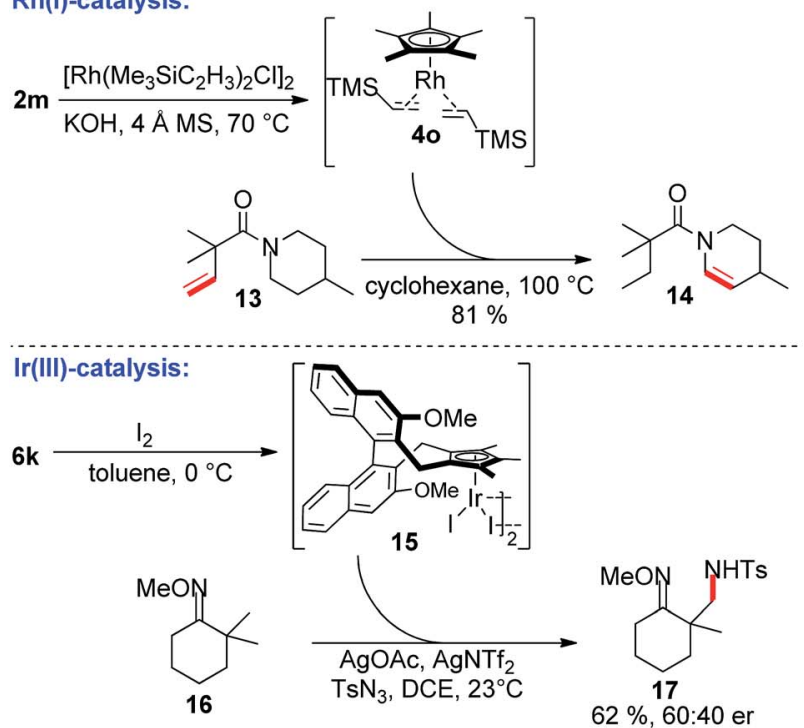

Scheme 3 In situ Cp metal complex preparation and direct application in $\mathrm{Rh}(\mathrm{III}), \mathrm{Rh}(\mathrm{I})$ and Ir(III) catalysis. PMP = 4-methoxyphenyl. 
Fig. 2b clearly shows that the substitution pattern strongly influences the TS1 barrier height, with the slower substrate 2d (21.1 kcal $\mathrm{mol}^{-1}$ ) having the highest barrier and the fastest substrate, $p-\mathrm{NO}_{2}$ bearing 2p, having the lowest $\left(15.4 \mathrm{kcal} \mathrm{mol}^{-1}\right)$.

Besides base-free complexation avoiding toxic solvents and bases, the instant preparation and direct subsequent use in catalysis of the formed Cp-metal complex is a salient feature of this protocol (Scheme 3). As an example for Rh(III)-catalysis, the regioselective dihydroisoquinolone formation with terminal 1decene is shown using the in situ formed $\mathrm{Cp}^{\mathrm{t}} \mathrm{Rh}(\mathrm{I})$ complex $\mathbf{4 p}$. This protocol provides $\mathbf{1 0}$ in similar yield and regioselectivity as previously reported by Rovis with an isolated $\mathrm{Cp}^{\mathrm{t}} \mathrm{Rh}$ complex. ${ }^{3 a, b}$ The simple precatalyst $\mathbf{2 d}$ can be used to access $\mathbf{4 a}$, which in turn was used for the synthesis of isoquinolone 12 with reversed regioselectivity, again with comparable yield and regioselectivity as previously observed by us. ${ }^{18}$ The vinyl-TMS bearing complex 4o is hardly accessible from the reduction of $\left[\mathrm{Cp} * \mathrm{RhCl}_{2}\right]$ and simplifies applications in $\mathrm{Cp} * \mathrm{Rh}(\mathrm{I})$ catalysis. For instance, it is a competent catalyst for intramolecular transfer olefinations ${ }^{\mathbf{1 9}}$ of piperidinyl amide 13 providing enamide 14. In addition, chiral $\mathrm{Cp}^{\mathrm{x}} \operatorname{Ir}(\mathrm{I})$ complex $\mathbf{6 k}$ could be smoothly oxidized with iodine to the Ir(III) species 15. This catalyst provides promising preliminary results for oximedirected asymmetric $\mathrm{C}\left(\mathrm{sp}^{3}\right)-\mathrm{H}$ functionalizations of substrate $\mathbf{1 6}$ yielding the tosylamide product $\mathbf{1 7} .^{20}$

\section{Conclusions}

In summary, we have reported a new complexation strategy to access late transition-metal $\mathrm{Cp}$ complexes. Rapid $\beta$-carbon elimination of cyclopentadienyl carbinols in the presence of a common metal precursor provides access to a wide range of $\mathrm{Cp}$ metal complexes. The advantages of this process are the direct and flexible use of storable pre-ligands. No auxiliary base is required and the $\mathrm{Cp}$ complexes can be prepared in situ in the reaction vessel. This protocol should enhance the convenience in applying these complexes in catalysis and allow for more rapid exploitation of the untapped potential of tailored $\mathrm{Cp}$ ligands. In particular, we expect this is a door-opener for further application of chiral $\mathrm{Cp}^{*}$ metal complexes in catalysis.

\section{Conflicts of interest}

There are no conflicts to declare.

\section{Acknowledgements}

This work is supported by the EPFL and the Swiss National Science Foundation Consolidator Grant no. 157741. G. S. thanks the EC 7th Framework Program project REGPOT-CT2013-316149-InnovaBalt.

\section{Notes and references}

\footnotetext{
1 J. Hartwig, Organotransition Metal Chemistry: From Bonding to Catalysis, University Science Books, Sausalito, CA, 2010.
}

2 (a) T. A. Davis, C. Wang and T. Rovis, Synlett, 2015, 26, 1520; (b) T. Piou and T. Rovis, J. Am. Chem. Soc., 2014, 136, 11292; (c) T. Piou and T. Rovis, Nature, 2015, 527, 86; (d) F. Romanov-Michailidis, K. F. Sedillo, J. M. Neely and T. Rovis, J. Am. Chem. Soc., 2015, 137, 8892; (e) Y. Hoshino, Y. Shibata and K. Tanaka, Adv. Synth. Catal., 2014, 356, 1577; (f) T. K. Hyster and T. Rovis, Chem. Commun., 2011, 47, 11846; $(g)$ Y. Shibata and K. Tanaka, Angew. Chem., Int. Ed., 2011, 50, 10917.

3 (a) T. K. Hyster, D. M. Dalton and T. Rovis, Chem. Sci., 2015, 6, 254; (b) T. K. Hyster and T. Rovis, Chem. Sci., 2011, 2, 1606; (c) J. M. Neely and T. Rovis, J. Am. Chem. Soc., 2014, 136, 2735; (d) M. D. Wodrich, B. Ye, J. F. Gonthier, C. Corminboeuf and N. Cramer, Chem. -Eur. J., 2014, 20, 15409.

4 For a recent review see: (a) C. G. Newton, D. Kossler and N. Cramer, J. Am. Chem. Soc., 2016, 138, 3935; (b) B. Ye and N. Cramer, Acc. Chem. Res., 2015, 48, 1308for selected examples, see: (c) G. Erker and A. A. H. van der Zeijden, Angew. Chem., Int. Ed., 1990, 29, 512; (d) B. Ye and N. Cramer, Science, 2012, 338, 504; (e) T. K. Hyster, L. Knorr, T. R. Ward and T. Rovis, Science, 2012, 338, 500; (f) B. Ye and N. Cramer, J. Am. Chem. Soc., 2013, 135, 636; (g) D. Kossler and N. Cramer, J. Am. Chem. Soc., 2015, 137, 12478; (h) G. Song, W. N. O. Wylie and Z. Hou, J. Am. Chem. Soc., 2014, 136, 12209; (i) M. Dieckmann, Y.-S. Jang and N. Cramer, Angew. Chem., Int. Ed., 2015, 127, 12317.

5 (a) R. Dubois, US4962253 A, The Dow Chemical, 1990; $(b)$ R. B. King, Inorg. Chem., 1963, 2, 528; (c) M. D. Rausch and R. A. Genetti, J. Org. Chem., 1970, 35, 3888; (d) N. Weding, R. Jackstell, H. Jiao, A. Spannenberg and M. Hapke, Adv. Synth. Catal., 2011, 353, 3423; (e) C. White, A. Yates, P. M. Maitlis and D. M. Heinekey, in Inorg. Synth., John Wiley \& Sons, Inc., 2007, p. 228; $(f)$ H. Chen, J. Hartwig and T. C. Semple, WO 01/64689 A1, Shell Internationale Research Maatschappij B.V., Yale University, 2001.

6 (a) T. E. Bitterwolf, T. L. Hubler and A. L. Rheingold, J. Organomet. Chem., 1992, 431, 199; (b) B. G. Conway and M. D. Rausch, Organometallics, 1985, 4, 688; (c) P. G. Gassman and C. H. Winter, J. Am. Chem. Soc., 1986, 108, 4228; (d) S. S. Jones, M. D. Rausch and T. E. Bitterwolf, J. Organomet. Chem., 1993, 450, 27.

7 For a review, see: (a) D. J. Mack and J. T. Njardarson, ACS Catal., 2013, 3, 272; (b) T. Seiser and N. Cramer, Synlett, 2011, 4, 449; (c) M. Murakami and T. Matsuda, Chem. Commun., 2011, 47, 1100; (d) K. Ruhland, Eur. J. Org. Chem., 2012, 14, 2683; (e) M. Miura and T. Satoh, in Palladium in Organic Synthesis, ed. J. Tsuji, Springer Berlin Heidelberg, Berlin, Heidelberg, 2005, pp. 1-20.

8 For selected examples, see: (a) R. Shintani, K. Takatsu, T. Katoh, T. Nishimura and T. Hayashi, Angew. Chem., Int. Ed., 2008, 47, 1447; (b) A. Horita, H. Tsurugi, A. Funayama, T. Satoh and M. Miura, Org. Lett., 2007, 9, 2231; (c) T. Nishimura, T. Katoh, K. Takatsu, R. Shintani and T. Hayashi, J. Am. Chem. Soc., 2007, 129, 14158; (d) R. Shintani, K. Takatsu, T. Katoh, T. Nishimura and T. Hayashi, Angew. Chem., Int. Ed., 2008, 47, 1447; (e) A. Funayama, T. Satoh and M. Miura, J. Am. Chem. Soc., 
2005, 127, 15354; $(f)$ T. Nishimura, H. Araki, Y. Maeda and S. Uemura, Org. Lett., 2003, 5, 2997.

9 For selected examples, see: (a) X. Yu, J. Wang, W. Guo, Y. Tian and J. Wang, Organometallics, 2016, 35, 1876; (b) E. Ozkal, B. Cacherat and B. Morandi, ACS Catal., 2015, 5, 6458; (c) J. R. Bour, J. C. Green, V. J. Winton and J. B. Johnson, J. Org. Chem., 2013, 78, 1665; (d) H. Li, Y. Li, X.-S. Zhang, K. Chen, X. Wang and Z.-J. Shi, J. Am. Chem. Soc., 2011, 133, 15244; (e) T. Uto, M. Shimizu, K. Ueura, H. Tsurugi, T. Satoh and M. Miura, J. Org. Chem., 2008, 73, 298; (f) M. Nakano, T. Satoh and M. Miura, J. Org. Chem., 2006, 71, 8309; (g) P. Zhao, C. D. Incarvito and J. F. Hartwig, J. Am. Chem. Soc., 2006, 128, 3124; (h) Y. Terao, M. Nomoto, T. Satoh, M. Miura and M. Nomura, J. Org. Chem., 2004, 69, 6942; (i) Y. Terao, H. Wakui, T. Satoh, M. Miura and M. Nomura, J. Am. Chem. Soc., 2001, 123, 10407.

10 (a) N. Ishida, N. Ishikawa, S. Sawano, Y. Masuda and M. Murakami, Chem. Commun., 2015, 51, 1882; (b) L. Souillart and N. Cramer, Chem. Sci., 2014, 5, 837; (c) N. Ishida, S. Sawano and M. Murakami, Chem. Commun., 2012, 48, 1973; (d) N. Ishida, S. Sawano, Y. Masuda and M. Murakami, J. Am. Chem. Soc., 2012, 134, 17502; (e) T. Seiser and N. Cramer, J. Am. Chem. Soc., 2010, 132, 5340; $(f)$ T. Seiser and N. Cramer, Chem.-Eur. J., 2010, 16, 3383; $(g)$ T. Seiser, O. A. Roth and N. Cramer, Angew. Chem., Int. Ed., 2009, 48, 6320; (h) M. Shigeno, T. Yamamoto and M. Murakami, Chem.-Eur. J., 2009, 15, 12929; ( $i$ ) S. Matsumura, Y. Maeda, T. Nishimura and S. Uemura, J. Am. Chem. Soc., 2003, 125, 8862; (j) R. C. Laroc, Ch and K. Reddy, Org. Lett., 2000, 1, 3325; $(k)$ T. Nishimura and S. Uemura, J. Am. Chem. Soc., 1999, 121, 11010.

11 P. R. Khoury, J. D. Goddard and W. Tam, Tetrahedron, 2004, 60, 8103.
12 For a review see: (a) H. Yorimitsu and K. Oshima, Bull. Chem. Soc. Jpn., 2009, 82, 778for selected examples, see: (b) M. Waibel and N. Cramer, Angew. Chem., Int. Ed., 2010, 49, 4455; (c) R. Wakabayashi, D. Fuijino, S. Hayashi, H. Yorimitsu and K. Oshima, J. Org. Chem., 2010, 75, 4337; (d) M. Iwasaki, S. Hayashi, K. Hirano, H. Yorimitsu and K. Oshima, J. Am. Chem. Soc., 2007, 129, 4463; (e) S. Hayashi, K. Hirano, H. Yorimitsu and K. Oshima, J. Am. Chem. Soc., 2006, 128, 2210; $(f)$ T. Kondo, K. Kodoi, E. Nishinaga, T. Okada, Y. Morisaki, Y. Watanbe and T. Mitsudo, J. Am. Chem. Soc., 1999, 120, 5587; $(g)$ J. Nokami, K. Yoshizane, H. Matsuura and S. Sumida, J. Am. Chem. Soc., 1998, 120, 6609.

13 M. Uemura, K. Yagi, M. Iwasaki, K. Nomura, H. Yorimitsu and K. Oshima, Tetrahedron, 2006, 62, 3523.

14 (a) J. P. Perdew, K. Burke and M. Ernzerhof, Phys. Rev. Lett., 1996, 77, 3865; (b) C. Adamo and V. Barone, J. Chem. Phys., 1999, 110, 6158.

15 (a) S. N. Steinmann and C. Corminboeuf, J. Chem. Theory Comput., 2010, 6, 1990; (b) S. N. Steinmann and C. Corminboeuf, Chimia, 2011, 65, 240; (c) S. N. Steinmann and C. Corminboeuf, J. Chem. Phys., 2011, 134, 044117; (d) S. N. Steinmann and C. Corminboeuf, J. Chem. Theory Comput., 2011, 7, 3567.

16 (a) Y. Zhao and D. G. Truhlar, Acc. Chem. Res., 2008, 41, 157; (b) Y. Zhao and D. G. Truhlar, Theor. Chem. Acc., 2008, 120, 215.

17 A. Klamt, WIREs Comput. Mol. Sci., 2011, 1, 699.

18 M. D. Wodrich, B. Ye, J. F. Gonthier, C. Corminboeuf and N. Cramer, Chem. Eur. J., 2014, 20, 15409.

19 (a) B. DeBoef, S. J. Pastine and D. Sames, J. Am. Chem. Soc., 2004, 126, 6556; (b) C. P. Langes, P. S. White and M. Brookhart, J. Am. Chem. Soc., 1999, 121, 4385.

20 T. Kang, Y. Kim, D. Lee, Z. Wang and S. Chang, J. Am. Chem. Soc., 2014, 136, 4141. 